\title{
Supplemental materials:
}

\section{The relationship between crystal structure, texture and macroscopic properties}

\section{of tetragonal $(\mathrm{Pb}, \mathrm{La})(\mathrm{Zr}, \mathrm{Ti}) \mathrm{O}_{3}$ ferroelectrics investigated by in-situ high-energy} \section{synchrotron diffraction}

Longlong Fan, ${ }^{\mathrm{a}, ~}$ Linxing Zhang, ${ }^{\mathrm{c}}$ Yang Ren, ${ }^{\mathrm{d}}$ Hui Liu, ${ }^{\mathrm{b}}$ Xianran Xing, ${ }^{\mathrm{e}}$ Jun Chen ${ }^{\mathrm{b}, \mathrm{e},}$ *

a College of Physics and Materials Science, Tianjin Normal University, Tianjin 300387, China

${ }^{\mathrm{b}}$ School of Mathematics and Physics, University of Science and Technology Beijing, Beijing 100083, China

${ }^{\mathrm{c}}$ Institute for Advanced Materials and Technology, University of Science and Technology Beijing, Beijing 100083, China

d X-Ray Science Division, Advanced Photon Source, Argonne National Laboratory, Argonne, Illinois 60439, USA

e. Beijing Advanced Innovation Center for Materials Genome Engineering, Institute of Solid State Chemistry, University of Science and Technology Beijing, Beijing 100083, China

Table S1. Structural parameters of tetragonal $(P 4 \mathrm{~mm})$ LaPZT50 at electric fields of $6.0 \mathrm{kV} / \mathrm{mm}$ and $0 \mathrm{kV} / \mathrm{mm}$. In consideration of the use of high-energy X-ray photons, the anisotropic displacement parameters were merely refined for the heavy element of $\mathrm{Pb}$.

\begin{tabular}{lll}
\hline \multicolumn{1}{c}{ Electric Field } & \multicolumn{1}{c}{$6.0 \mathrm{kV} / \mathrm{mm}$} & $0 \mathrm{kV} / \mathrm{mm}$ (poled) \\
\hline$a / b(\AA)$ & $4.03218(7)$ & $4.03149(6)$ \\
$c(\AA)$ & $4.13569(7)$ & $4.13592(6)$ \\
$U_{11,22}-\mathrm{Pb}\left(\AA^{2}\right)$ & $0.03020(4)$ & $0.02986(3)$ \\
$U_{33}-\mathrm{Pb}\left(\AA^{2}\right)$ & $0.01230(1)$ & $0.01409(1)$ \\
$z-\mathrm{Zr} / \mathrm{Ti}$ & $0.55083(18)$ & $0.55024(18)$ \\
$z-\mathrm{O} 1$ & $0.10320(77)$ & $0.10514(73)$ \\
$z-\mathrm{O} 2$ & $0.61677(54)$ & $0.61660(51)$ \\
$\mathrm{Phase}$ fraction$(\%)$ & $86.30(0.56)$ & $87.21(0.50)$ \\
$\mathrm{Bragg} \mathrm{R}-$ factor & 4.33 & 3.64 \\
$R_{\mathrm{p}}$ & 7.76 & 7.51 \\
$R_{\mathrm{wp}}$ & 6.85 & 6.54 \\
$\chi^{2}$ & 2.26 & 2.05 \\
\hline
\end{tabular}




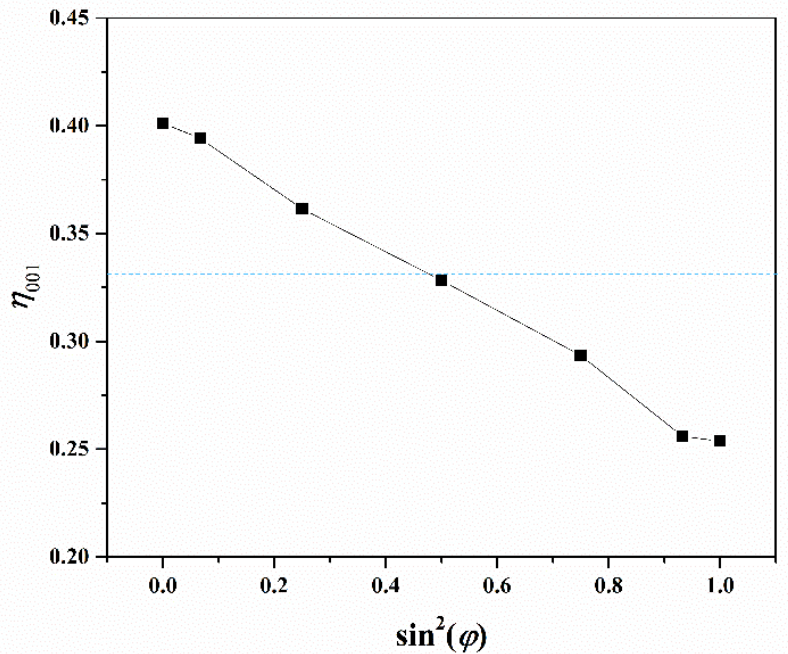

Fig. S1. Under the electrical loading of $6 \mathrm{kV} / \mathrm{mm}$, the absolute domain volume change of 001 -orientated at various sectors, here $\varphi$ is defined as the angle of sector. 